\title{
Mechanical Properties and Durability of Recycled Aggregate Permeable Concrete
}

\author{
Lifang Liu ${ }^{1}$, Bo Dong ${ }^{2,3 *}$ \\ ${ }^{1}$ School of Architectural Engineering, Ningbo Polytechnic, Ningbo 315800, China \\ ${ }^{2}$ School of Architectural Engineering, Chuzhou Polytechnic College, Chuzhou 239000, China \\ ${ }^{3}$ College of Environmental Science and Engineering, Donghua University, Shanghai 201600, China
}

Corresponding Author Email: dongbo@chzc.edu.cn

https://doi.org/10.18280/rcma.310307

Received: 16 January 2021

Accepted: 20 April 2021

\section{Keywords:}

recycled aggregate, permeable concrete, mechanical properties, durability

\begin{abstract}
The recycled aggregate permeable concrete made of reused construction wastes is very important for realizing the sustainable development of the construction industry, it can alleviate the adverse impact of surface runoff during storm and the urban heat island effect. Therefore, this paper studied the mechanical properties and durability of recycled aggregate permeable concrete. At first, a few properties of the target material, including bulk density, moisture content, water absorption, compressive strength, and water permeability coefficient, were tested respectively. Then, based on the orthogonal test, the performance of the target material was analyzed, and the analysis steps of the range analysis method and the variance analysis method in the orthogonal test were given. At last, the mechanical properties and durability of the target material were tested via experiments, and the relevant test results and analysis were elaborated.
\end{abstract}

\section{INTRODUCTION}

As the urbanization progress is accelerating and the construction industry is developing rapidly, more and more concrete construction wastes have been produced, and burying them in nearby places has brought great burden to the ecological environment [1-4]. At present, the research topics of the re-use of concrete construction wastes, and the development and performance of the recycled aggregate permeable concrete have received wide attention from field scholars at home and abroad, which is of great significance for the sustainable development of the construction industry. In cities, the hard road pavement built by dense concrete is impermeable and airtight, which is the main reason for the surface runoff during storm and the urban heat island effect [59]. The research on recycled aggregate permeable concrete meets the requirement of the times for low carbon emission, environmental protection, and sustainable development, and it has certain social, economic, and environmental benefits.

The complex and random sources of recycled aggregates result in differences in the strength and other properties of the recycled concrete [10-17]. Ghorbel et al. [18] tested the mechanical properties of recycled concrete under the condition of double corrosion of salt and freezing, studied the mass loss of the concrete under different corrosion types and different corrosion times, and explored the variation law of the bonding of concrete and steel bars and its splitting and tensile properties. Ilango et al. [19] designed a loading test for natural aggregate concrete and recycled brick-mixed aggregate concrete, and analyzed their differences in loading process, fracture characteristics, ductility, and durability. Scholars Sunayana and Barai [20] tested the performance of recycled aggregate permeable concrete and natural aggregate concrete under small eccentric compression, and concluded that the two types of concrete had the same stress-bearing stages and different axial compressive strengths. Nematzadeh and Baradaran-Nasiria [21] explored the principle of water storage and release of the porous media inside the concrete based on the water transmission mechanism of concrete, and analyzed the influence mechanism of the core-shell structure and the outer coating layer of the aggregate on the water storage and release performance of the recycled aggregate. Ali and Qureshi [22] used the absolute volume method to test the water-cement ratio, aggregate-cement ratio, and degree of compaction of the recycled aggregate permeable concrete, and discussed the durability of the concrete under different aggregate conditions. Gonzalez-Corominas et al. [23] studied the load-freeze/thaw characteristics of coarse aggregate selfcompacting concrete under the combined actions of multiple degrading environmental factors, through freeze-thaw tests, they also analyzed the failure mode of concrete test pieces and the variation laws of the compressive strength, tensile strength, bending strength, maximum crack width, and axial compressive strength of the concrete test pieces.

Existing researches mostly concerned about the design of the mixing ratio of certain aggregate in the concrete, or the test on the performance of ordinary permeable concrete in terms of mechanics, permeability, and frost resistance [24-29], and very few of them have paid attention to the basic properties of recycled aggregate permeable concrete made of reused construction wastes. To fill in such research gap, this paper studied the mechanical properties and durability of recycled aggregate permeable concrete. The main content of this paper includes the following aspects: the second part tested a few properties of the recycled aggregate permeable concrete, including bulk density, moisture content, water absorption, compressive strength, and water permeability coefficient. The third part analyzed the performance of the recycled aggregate 
permeable concrete based on the orthogonal test, and gave the analysis steps of the range analysis method and the variance analysis method in the orthogonal test. The fourth part tested the mechanical properties and durability of the recycled aggregate permeable concrete via experiments, and gave the experimental results and analysis.

\section{PERFORMANCE TEST OF RECYCLED AGGREGATE PERMEABLE CONCRETE}

\subsection{Bulk density}

In order to obtain accurate results of the bulk density of the recycled aggregate, in the test, the vibration time of the measuring cylinder filled with aggregate placed on the vibrating table was set to be 15 minutes, and the mass of the measuring cylinder was recorded every 5 minutes.

Suppose: $D$ represents the volume of the measuring cylinder, $Q_{C W}$ represents the total mass of the measuring cylinder and water; $Q_{1}$ represents the mass of the measuring cylinder, $\zeta_{T T}$ represents the density of water at the test temperature $T_{T}$, then, the volume of the measuring cylinder could be determined via the following steps: first, clean debris inside the measuring cylinder, fill it up with water, and place it on the electronic scale; then, weigh the measuring cylinder, and record the value of $Q_{C W}$; at last, measure the water temperature and record it. The volume of the measuring cylinder $D$ could be calculated by Formula 1:

$$
D=\frac{Q_{C W}-Q_{1}}{\zeta_{T T}} \times 10^{3}
$$

Suppose $Q_{2}$ represents the mass of the measuring cylinder filled up with recycled aggregate, then the natural bulk density $\zeta$ of the recycled aggregate can be calculated by Formula 2:

$$
\zeta=\frac{Q_{2}-Q_{1}}{D} \times 10^{3}
$$

Suppose $\zeta_{P}$ represents the tapped bulk density of the recycled aggregate, then for the recycled aggregate, its tapped bulk porosity $\eta_{G}$ can be calculated by Formula 3:

$$
\eta_{G}=\left(1-\frac{\zeta}{\zeta_{P}} \times 100 \%\right)
$$

\subsection{Moisture content and water absorption}

During the design of the mixing ratio of the recycled aggregate permeable concrete, attentions should be paid to the mechanical properties, mixing performance and water consumption of the concrete test pieces, and these physical properties are greatly affected by the two parameters, the moisture content and water absorption of the recycled aggregate. Here are the measurement and calculation steps of the two parameters:

Step 1: Prepare test tools and materials

Test materials for the tests on moisture content and water absorption were: 4 piles of $1 \mathrm{~kg}$ recycled aggregate samples with approximately equal masses. The test tools were: plastic boxes, self-made aggregate sieve, and an electronic scale.
Step 2: Soak the aggregate in water and stand

Put the recycled aggregate into the self-made aggregate sieve and hang it in the plastic box, then pour water into the plastic box until the water surface is about $25 \mathrm{~mm}$ above the aggregate in the sieve, after that, stir the aggregate with a wooden stick to release the bubbles in the aggregate, let stand for 1 day.

Step 3: Measure the mass of the aggregate in water

Measure and record the mass of the wooden stick hanging the self-made aggregate sieve, then add the recycled aggregate to the sieve immersed in water, extract part of the water to keep the water level unchanged, and record $Q_{C W}$, the mass of the aggregate in water.

Step 4: Measure the mass of the surface-dry aggregate

Take the recycled aggregate out of the water and the sieve, drain the excess water, rub it with dry towel and toilet paper to make the surface of the aggregate dry under the condition of no missing fine particles, then, measure $Q_{W D}$, the mass of the aggregate under such state, and record it.

Step 5: Measure the dry mass of the aggregate

Dry the surface-dry aggregate at $110^{\circ} \mathrm{C} \pm 6^{\circ} \mathrm{C}$, and then measure its mass, when the mass no longer changes, record the mass of the aggregate under this state as $Q_{D}$.

After obtain the values of $Q_{W D}$ and $Q_{D}$, the water absorption rate $\xi_{a}$ of the recycled aggregate can be calculated by Formula 4:

$$
\xi_{a}=\frac{Q_{W D}-Q_{D}}{Q_{D}} \times 100 \%
$$

Suppose $Q_{A}$ represents the mass of the water-soaked aggregate before drying, then the moisture content $\theta$ can be calculated by Formula 5:

$$
\theta=\frac{Q_{A}-Q_{D}}{Q_{D}} \times 100 \%
$$

And the additional water consumption rate $\xi_{T}$ of the recycled aggregate can be calculated by Formula 6:

$$
\xi_{T}=\xi_{a}-\theta
$$

\subsection{Compressive strength}

Suppose: $G$ and $S$ respectively represent the failure load and stress-bearing area of the recycled aggregate permeable concrete test piece, then the compressive strength $R_{C}$ of the test piece can be calculated by Formula 7:

$$
R_{C}=\frac{G}{S}
$$

The speed of the compressive load applied on the test pieces was set to $0.4 \mathrm{MPa} / \mathrm{s}$, and the precise value of $R_{C}$ took 0.01 $M P a$. The measurement tests were divided into 3 groups, each group contained 4 test pieces of equal volume and shape. After the measurement was completed, the average value of the compressive strength of all test pieces was taken as the measured value of the compressive strength of the recycled aggregate permeable concrete. 


\subsection{Permeability coefficient}

This paper chose to measure and calculate the permeability coefficient of the recycled aggregate permeable concrete based on Darcy's law. The specific steps are given below:

Step 1: Seal the test container and place the test piece

Take a sealed steel cylinder and a permeable steel cylinder (the two cylinders have a same radius) and a concrete test piece, place the concrete test piece into the bottom of the sealed steel cylinder and use silica gel and paraffin to seal the joints, then, place the connected sealed steel cylinder and the permeable steel cylinder into a glass container with a water outlet.

Step 2: Inject water and maintain the balance of inlet water and outlet water

Inject water into the sealed steel cylinder through the permeable steel cylinder, the water enters the glass container through the water permeation of the test piece; then, continue to inject water until there's water flowing out from the water outlet of the glass container, and the amount of inlet water is equal to the amount of outlet water.

Step 3: Measure water permeability

Suppose: $V$ represents the reference value of the water permeation volume of the concrete test piece, use a stopwatch to record the time $h$ when the actual water permeation volume reaches $V$, and the water temperature $T_{W}$.

Suppose $L$ and $S$ respectively represent the thickness and area of the recycled aggregate permeable concrete test piece, $w$ represents the water head, then the water permeability coefficient $P E_{T W}$ of the recycled aggregate permeable concrete test piece can be calculated by Formula 8:

$$
P E_{T W}=V \times L /(S \times w \times h)
$$

In order to reduce the influence of water temperature on the dynamic viscous force and permeability of water, this paper uniformly converted the water permeability coefficients under different water temperature conditions into that under the standard temperature of $15^{\circ} \mathrm{C}$, which had improved the comparability of the water permeability of the concrete under different working conditions. The conversion formula is $P E_{15}=\lambda \times P E_{T W}$, wherein $\lambda$ is the correction coefficient of the conversion process.

\section{PERFORMANCE ANALYSIS OF THE RECYCLED AGGREGATE PERMEABLE CONCRETE BASED ON ORTHOGONAL TEST}

To better test the overall performance of the recycled aggregate permeable concrete, this study selected a few representative test combinations to perform the orthogonal test. Figure 1 gives a comparison of the cube grids of the traditional performance analysis method and the orthogonal test analysis method. As can be intuitively seen from the figure, the test points selected by the orthogonal test method are quite representative. The specific steps of the test are described as follows:

Step 1: Clarify the purpose of the research on the mechanical properties and durability of recycled aggregate permeable concrete, determine the relevant qualitative and quantitative indicators, and comprehensively consider and determine as many static and dynamic factors as possible;

Step 2: Evaluate the importance, relevance, and change level of all factors, and delete factors with low importance and high relevance based on actual conditions; as for factors with high importance and low relevance, within a specified variation range, set more intervals to obtain more measurement results;

Step 3: Based on the existing test tools and materials, predict the tests that can be completed and the possible test progress;

Step 4: The number and importance of the selected factors, the mechanical properties of the recycled aggregate permeable concrete, and the precision requirements of durability test jointly determine the size of the selected orthogonal table. More factors, higher importance, and higher precision of the test require a larger-size orthogonal table; on the contrary, a smaller-size orthogonal table will be used;

Step 5: Formulate a test plan for the mechanical properties and durability of the recycled aggregate permeable concrete, and carry out the tests according to the steps listed in the plan;

Step 6: Analyze the parameters and indicators obtained from the test and calculation; use the range analysis method to rank the influence of various factors on the mechanical properties and durability of the recycled aggregate permeable concrete, then, use the variance analysis method to further judge the significance of the influence of each factor and make further judgement to obtain reasonable analysis conclusions.

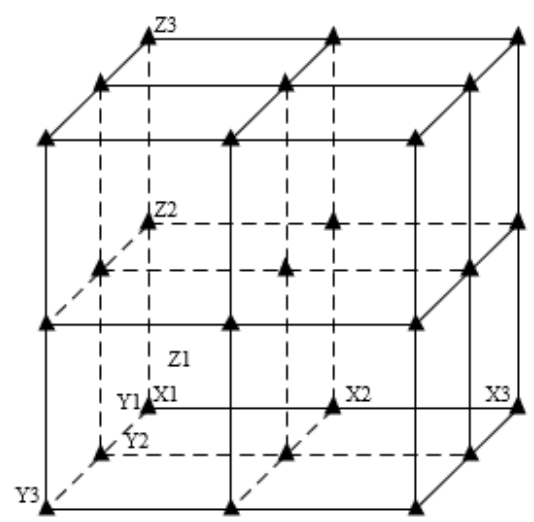

(a)

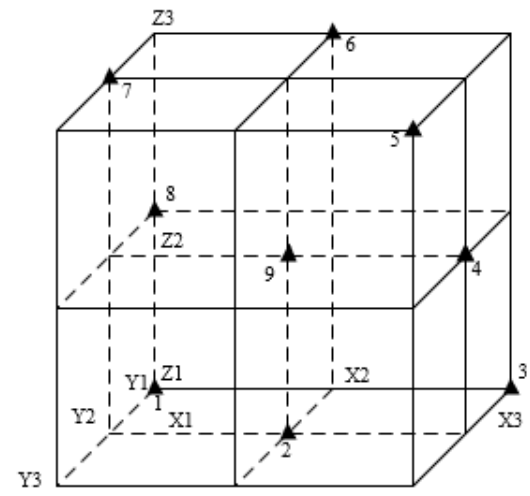

(b)

Figure 1. Comparison of the traditional performance analysis method and the orthogonal test analysis method

Suppose: among the factors in the $i$-th column of the orthogonal table with randomly arranged table head, the sum of the indicators of the mechanical properties and durability test of the recycled aggregate permeable concrete corresponding to the $j$-th measurement interval is represented by $S I_{i j}$; the number of measurements within a specified variation range is represented by $r$, then, the arithmetic mean $\varphi_{i j}$ of $S I_{i j}$ can be calculated by Formula 9: 


$$
\phi_{i j}=\frac{S I_{i j}}{r}
$$

The range $\sigma_{i}$ between the arithmetic mean $\varphi_{i j}$ corresponding to different measurement intervals of factors in the $i$-th column could be calculated by Formula 10:

$$
\sigma_{i}=\max \left\{\phi_{i j}\right\}-\min \left\{\phi_{i j}\right\}
$$

As can be seen from the above formula, $\sigma_{i}$ describes the reasonableness of the measurement interval of factors in the $i$ th column, to a certain extent, it also reflects the extent to which the measurement interval can faithfully reflect the actual variation details of the measurement results of the test indicator. Suppose: $\gamma$ represents the conversion coefficient related to the measurement interval of a factor, $s$ represents the number of repeated tests under the condition of each measurement interval for that factor, then the converted $\sigma_{I}^{\prime}$ value can be calculated by Formula 11:

$$
\sigma_{i}^{\prime}=d \sigma_{i} \sqrt{s}
$$

The variance analysis method can make up for the defects of the range analysis method, it can compare and examine the deviations caused by condition change or accidental error through the statistics $F$, and then judge the significance of the effect of each factor.

Suppose: there're $n$ static and dynamic factors that have been selected; for each factor, within the specified variation range, $m_{L}$ measurement intervals have been set; for each measurement interval, the test is carried out for $s$ times, and the total number of tests is $m$, which satisfies $m=n \times m_{u} \times s$; the measurement results of the test indicator are represented by $a_{1}$, $a_{2}, \ldots \ldots, a_{m}$. The specific analysis steps are described as follows:

Step 1: Solve the sum of squares of test deviations

During the test, due to the difference in the factor measurement intervals and the existence of test deviations, there're certain differences in the measurement results of the test indicators, and the sum of squares of the total deviation $P_{S S}$ increases with such difference. Formula 12 calculates the average value of the measurement results of the test indicators:

$$
\tilde{a}=\frac{1}{m} \sum_{l=1}^{m} a_{l}
$$

The calculation of $P_{S S}$ could be completed by Formula 13:

$$
P_{S S}=\sum_{l=1}^{m}\left(a_{l}-\tilde{a}\right)^{2}=\sum_{l=1}^{m} a_{l}^{2}-\frac{1}{m}\left(\sum_{l=1}^{m} a_{l}\right)^{2}
$$

Suppose: $W_{S S}$ represents the sum of the sums of squares of the measurement results of the test indicators, $O$ represents the average value of the sums of squares of the measurement results of the test indicators, then there is:

$$
W_{S S}=\sum_{l=1}^{m} a_{l}^{2} \quad O=\frac{1}{m}\left(\sum_{l=1}^{m} a_{l}\right)^{2}
$$

Then, $P_{S S}$ can be expressed as:

$$
P_{S S}=W_{S S}-O
$$

Step 2: Solve the sum of squares of the deviation of each factor

Suppose: $C$ is a factor that is randomly arranged in a certain column of the orthogonal table, $P_{C}$ represents the sum of squares of the deviation of factor $C$, and $a_{j k}$ represents the $k$-th test result of the $j$-th measurement interval of factor $C$, then there is:

$$
\sum_{j=1}^{m_{L}} \sum_{k=1}^{K} a_{j k}=\sum_{l=1}^{m} a_{l}
$$

The sum of squares of the deviation $P_{C}$ can be obtained based on the one-way analysis of variance shown as Formula 16 below:

$$
\begin{aligned}
& P_{C}=\frac{1}{K} \sum_{j=1}^{m_{L}}\left(\sum_{k=1}^{K} a_{j k}\right)^{2}-\frac{1}{m} \sum_{j=1}^{m_{L}}\left(\sum_{k=1}^{K} a_{j k}\right)^{2} \\
& =\frac{1}{K} \sum_{j=1}^{m_{L}} S I_{j}^{2}-\frac{1}{m}\left(\sum_{l=1}^{m} a_{l}\right)^{2}
\end{aligned}
$$

Suppose: $W_{C}$ represents the sum of the measurement results of test indicator corresponding to the $j$-th measurement interval, $O$ represents the corresponding average value of the sum of squares, then, there is:

$$
W_{C}=\frac{1}{K} \sum_{j=1}^{m_{L}} S I_{j}^{2} \quad S I_{j}=\frac{1}{m}\left(\sum_{l=1}^{m} a_{l}\right)^{2}
$$

Then, $P_{C}$ can be expressed as:

$$
P_{C}=W_{C}-O
$$

As can be seen from the above formula, $P_{C}$ describes the size of difference in the measurement results of test indicators of factor $C$ caused by the different measurement intervals.

Step 3: Solve $P_{W}$, the sum of squares of the deviation of test error

The difference between the $P_{S S}$ and $P_{S D S}$ (the sum of $P_{C}$ of all factors), namely the sum of squares of the deviation of test error $P_{W}$ can be calculated by Formula 20:

$$
P_{W}=P_{S S}-P_{S D S}
$$

Step 4: Calculate the degree of freedom of deviation and error

The total degree of freedom of the test can be calculated by Formula 21:

$$
g_{\text {total }}=m-1
$$

The degree of freedom of each factor can be calculated by Formula 22:

$$
g_{S D S}=m_{L}-1
$$

The degree of freedom of the test error can be calculated by Formula 23: 


$$
g_{W}=g_{\text {total }}-g_{S D S}
$$

Step 5: Calculate the mean sum of squares of deviation $H$.

Formula 24 gives the calculation result of $H_{S D S}$, the mean sum of squares of the deviation of each factor:

$$
H_{S D S}=\frac{P_{S D S}}{g_{S D S}}
$$

Formula 25 gives the calculation result of $H_{W}$, the mean sum of squares of the deviation of test error:

$$
H_{W}=\frac{P_{W}}{g_{W}}
$$

Step 6: Solve statistics F

Formula 26 gives the ratio of $H_{S D S}$ to $H_{W}$, namely the statistics $F$ which can reflect the degree of influence of each factor on the measurement results of the test indicators:

$$
G=\frac{H_{S D S}}{H_{W}}
$$

Step 7: Significance test of factors

Suppose: $\beta$ represents the significance level that characterizes the rationality of the measurement interval, find the test critical value $F_{\beta}\left(g_{S D S}, g_{W}\right)$ from the distribution table of statistics $\mathrm{F}$ and compare the size, then, the degree of influence of this factor on the measurement results of the test indicator could be obtained. The condition for judging that a factor has a significant influence is that the value of statistics $F$ is greater than $F_{0.1}\left(g_{S D S}, g_{W}\right)$; the condition for judging that a factor has a very significant influence is that the value of statistics $F$ is greater than $F_{0.05}\left(g_{S D S}, g_{W}\right)$; the condition for judging that a factor has a highly significant influence is that the value of statistics $F$ is greater than $F_{0.01}\left(g_{S D S}, g_{W}\right)$; under the rest conditions, it is considered that the influence is not significant.

\section{MECHANICAL PROPERTIES AND DURABILITY TEST RESULTS AND ANALYSIS}

The tests were carried out under the conditions that the replacement rate $\delta$ of the recycled aggregate was within the range of $[0,1]$, the measurement interval was 0.3 , and the particle size of the recycled aggregate was remained unchanged; when the water-cement ratio was within $[0.29,0.38]$, the tests were performed with 0.03 as the measurement interval. The compressive strength values of the recycled aggregate permeable concrete under different watercement ratios and recycled aggregate replacement rates were measured and calculated to determine the relationship between water-cement ratio, recycled aggregate replacement rate, and

\begin{tabular}{|c|c|c|c|c|c|c|}
\hline No. & $\begin{array}{l}\text { Particle size of } \\
\text { the aggregate }\end{array}$ & $\begin{array}{c}\text { Water- } \\
\text { cement ratio }\end{array}$ & $\begin{array}{c}\text { Compressive } \\
\text { strength when } \delta=0\end{array}$ & $\begin{array}{c}\text { Compressive strength } \\
\text { when } \delta=0.3\end{array}$ & $\begin{array}{c}\text { Compressive strength } \\
\text { when } \delta=0.6\end{array}$ & $\begin{array}{c}\text { Compressive strength } \\
\text { when } \delta=0.9\end{array}$ \\
\hline A4 & $4.72-9.6$ & 0.29 & 6.19 & 5.23 & 3.92 & 3.25 \\
\hline A7 & $4.72-9.6$ & 0.32 & 7.18 & 5.76 & 4.65 & 4.12 \\
\hline A 10 & $4.72-9.6$ & 0.35 & 6.45 & 6.47 & 6.32 & 6.38 \\
\hline A8 & $4.72-9.6$ & 0.38 & 6.13 & 4.61 & 4.08 & 4.06 \\
\hline A2 & $9.6-17$ & 0.29 & 6.79 & 5.82 & 4.49 & 4.31 \\
\hline A6 & $9.6-17$ & 0.32 & 7.42 & 6.25 & 5.37 & 4.62 \\
\hline A1 & $9.6-17$ & 0.35 & 6.57 & 6.37 & 6.72 & 6.98 \\
\hline A11 & $9.6-17$ & 0.38 & 6.51 & 6.29 & 5.81 & 5.42 \\
\hline A3 & $17-21$ & 0.29 & 5.43 & 3.75 & 2.53 & 2.19 \\
\hline A5 & $17-21$ & 0.32 & 7.52 & 5.04 & 3.19 & 2.18 \\
\hline A9 & $17-21$ & 0.35 & 6.27 & 5.31 & 4.05 & 4.37 \\
\hline $\mathrm{A} 12$ & $17-21$ & 0.38 & 6.55 & 5.21 & 3.85 & 4.09 \\
\hline
\end{tabular}
compressive strength. The test factors and results are shown in Table 1.

Table 1. Measured values of the compressive strength of test pieces

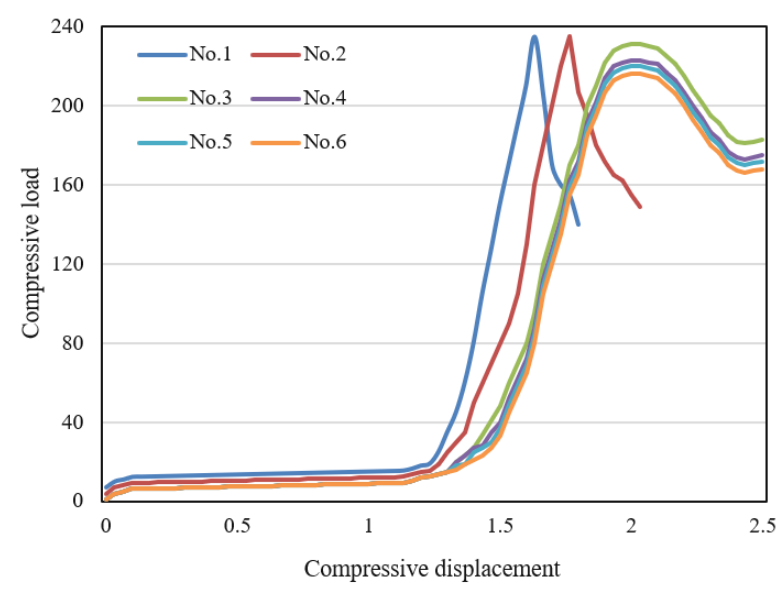

Figure 2. Compressive load-displacement curves of concrete test pieces

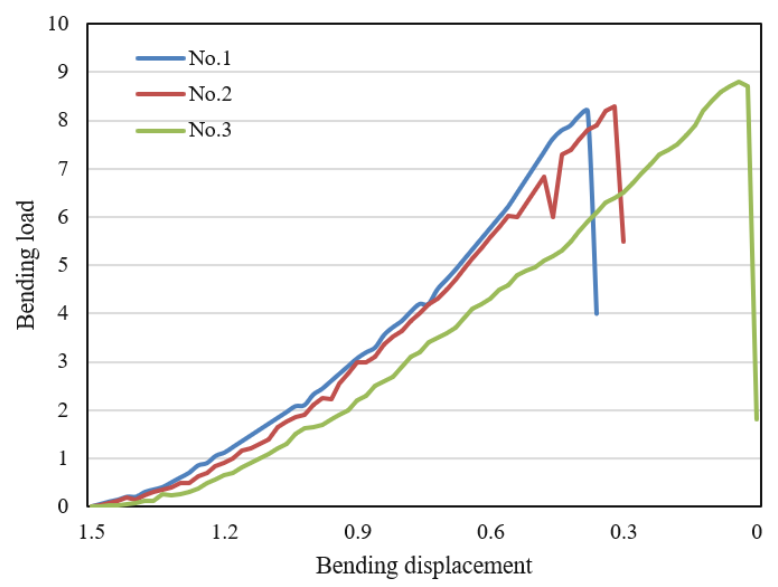

Figure 3. Bending load-displacement curves of concrete test pieces 
20 test pieces were subject to compression test and bending test, and the comparison of the test results showed that there's no significant difference in the failure mode of the test pieces with different mixing ratios. Figures 2 and 3 respectively give the compressive and bending load-displacement curves. According to Figure 2, with the increase of the compressive load, cracks begin to show up from the margin of the surface of the test pieces and gradually grow to the center of the

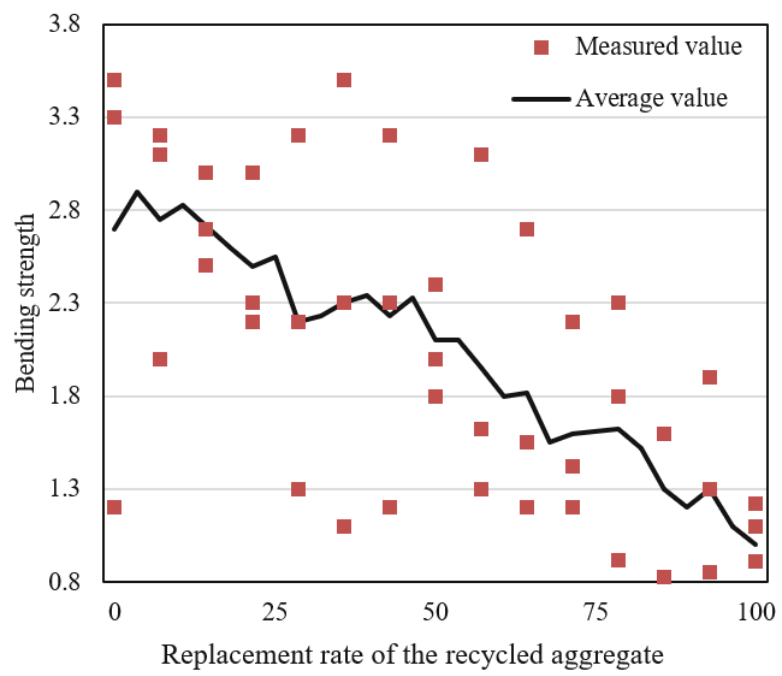

(a)

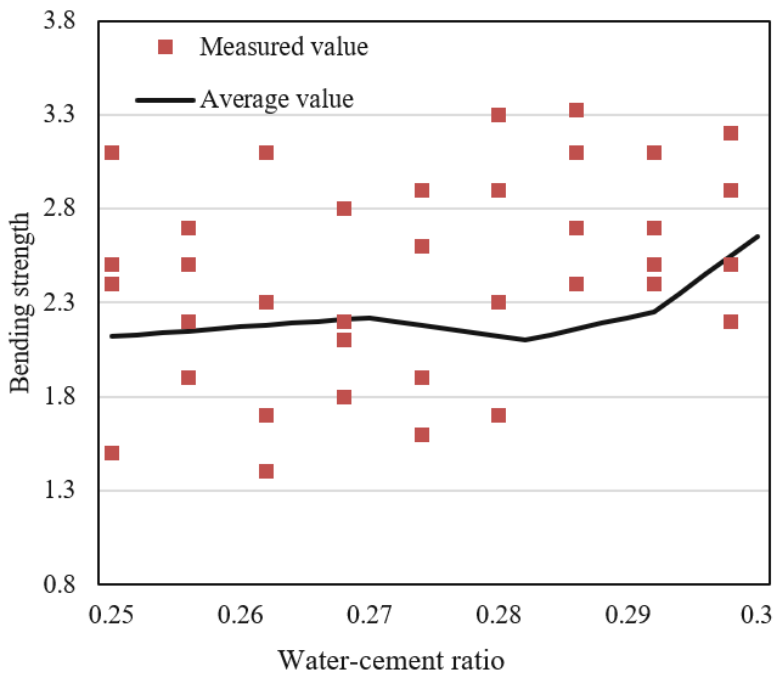

(c) surface, then, as the compressive load continuous to increase, vertical cracks form and extend to the inside of the test pieces, the surface damage develop and become brittle damage. According to Figure 3, with the increase of the bending load, cracks begin to show up in the middle part of the lower surface of the test pieces and constantly extend to the margin of the surface and the inside of the concrete, also, the surface damage develop and become brittle damage.

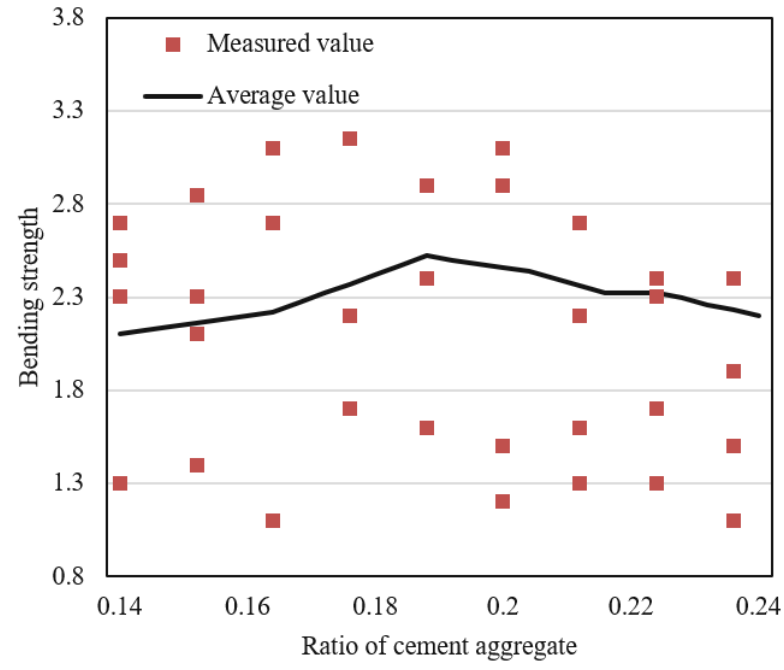

(b)

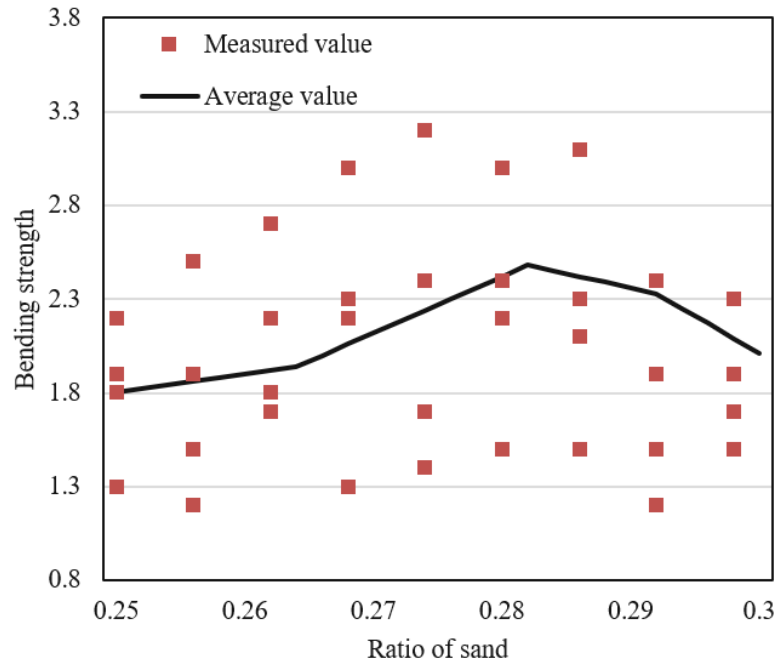

(d)

Figure 4. The influence of various factors on the bending strength of concrete

Figures 4 (a), (b), (c), and (d) respectively show the influence of a few factors (including the replacement rate of the recycled aggregate, the ratio of cement aggregate, the water-cement ratio, and the ratio of sand) on the bending strength of the recycled aggregate permeable concrete. As can be seen from the figure, as the replacement rate of recycled aggregate increases, the bending strength of the recycled aggregate permeable concrete shows a fluctuated decreasing trend. When the replacement rate of recycled aggregate increases from 0 to $25 \%$, the bending strength of the concrete gradually decreases; when the replacement rate of recycled aggregate increases from $25 \%$ to $48 \%$, the bending strength gradually increases; when the replacement rate of recycled aggregate exceeds $48 \%$, the bending strength keeps decreasing and drops to the lowest, indicating that when the mixing ratio of the recycled aggregate is at a low level, it has a certain effect on improving the bending strength of the recycled aggregate permeable concrete; however, when the mixing ratio of the recycled aggregate is at a high level, factors such as the ratio of the cement aggregate, the water-cement ratio, and the ratio of sand would bring greater adverse effects, so the improvement of the bending strength is not obvious. If the replacement rate of recycled aggregate is kept at a fixed value, then the bending strength of the concrete is less affected by the ratio of cement aggregate, the water-cement ratio, and the ratio of sand, and the fluctuations are not obvious.

Figure 5 shows the curves of the cumulative permeated water volume and the increment of permeated water volume. As can be seen from the figure, the porosity and total pore volume of the concrete test pieces were relatively small. After the recycled aggregate was added, the total porosity and average pore size of the concrete increased, but the proportions 
of harmful pores and very harmful pores increased significant as well. This is because the recycled aggregate is mixed into the concrete slurry as a waterproofing agent, after hydrolysis and condensation reactions, the generated hydrophobic groups would make the surface of the concrete slurry hydrophobic, and slow down the hydration of the concrete, resulting in an obvious increase in the proportion of harmful pores, and this phenomenon is consistent with the results of the test on the influence of various factors on the bending strength of concrete, the adding of recycled aggregate significantly reduced the compressive strength of the permeable concrete. Regarding the freeze-thaw durability of the recycled aggregate permeable concrete, the hydrophobic groups brought by recycled aggregate could act as the rigid waterproof layer of the test piece so the impermeability and the overall waterproofing ability of the test piece have been improved, water can hardly penetrate into the inside of the concrete, which would greatly reduce the degree of freeze-thaw deterioration of the concrete.

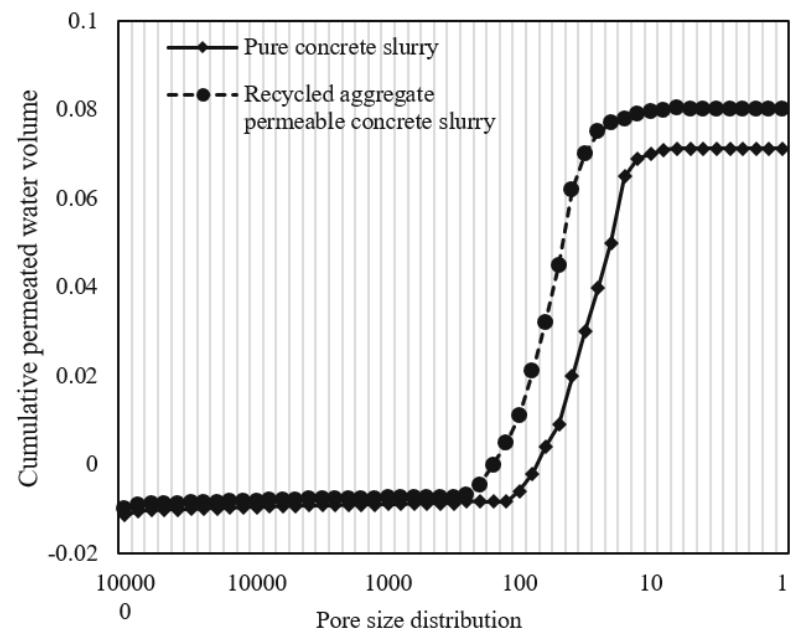

(a)

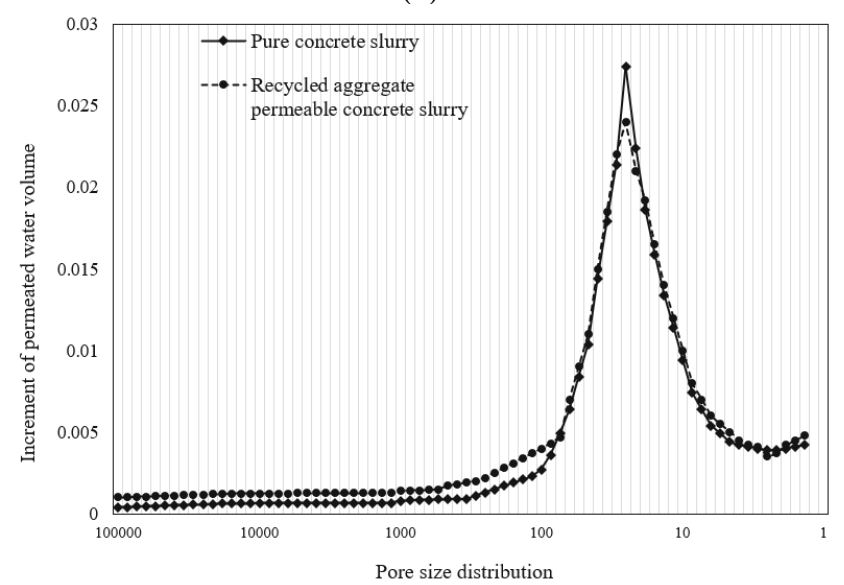

(b)

Figure 5. Curves of cumulative permeated water volume and permeated water volume increment

In order to further explore the degree of freeze-thaw deterioration and the freeze-thaw durability of the recycled aggregate permeable concrete, this study set a control group, a cement-based modification group, and a recycled aggregate modification group to compare the mass loss of the test pieces under different freeze-thaw cycles and explore the changes of the relative dynamic elastic modulus, see Figure 6 (a) and (b).

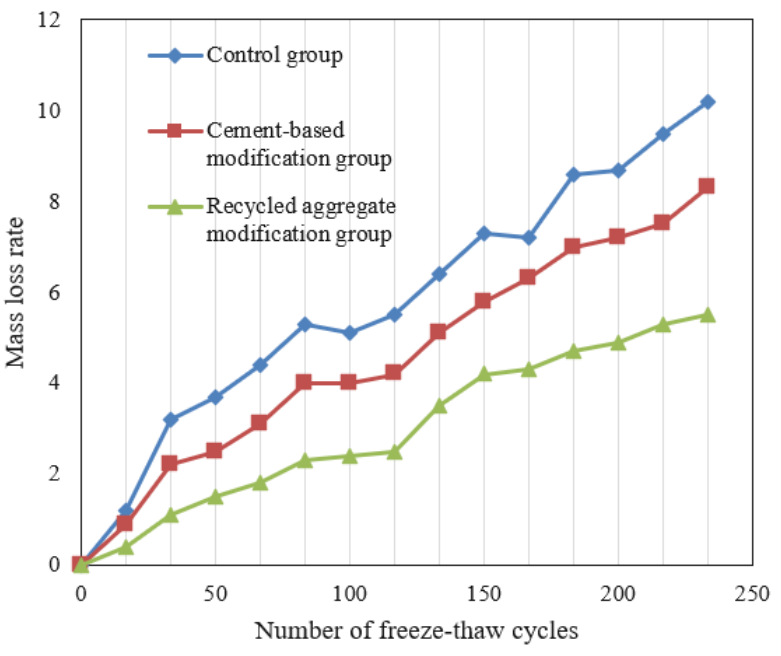

(a)

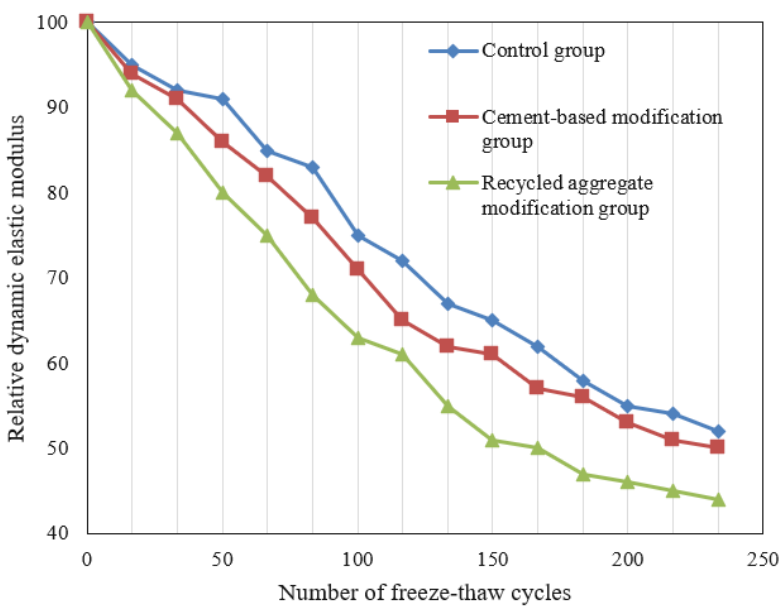

(b)

Figure 6. Curves of mass loss and relative dynamic elastic modulus of test pieces

With the increase of the number of freeze-thaw cycles, the mass loss of the three groups of test pieces increases continuously, while the relative dynamic elastic modulus decreases gradually. Among the three test groups, the change of the test pieces of the recycled aggregate permeable concrete was the smallest. When the number of freeze-thaw cycles reached about 250 times, the mass loss of the test pieces of the recycled aggregate permeable concrete test pieces exceeded $36.4 \%$, the relative dynamic elastic modulus increased by $17.1 \%$; compared with the test pieces of the control group, the mass loss exceeded $25.9 \%$, and the relative dynamic elastic modulus increased by $9.41 \%$, and the freeze-thaw durability of the concrete had been significantly improved.

\section{CONCLUSION}

This paper studied the mechanical properties and durability of recycled aggregate permeable concrete. First, the paper gave the methods for testing the bulk density, moisture content, water absorption, compressive strength, and water permeability coefficient of the recycled aggregate permeable concrete; then, it gave the analysis steps of the range analysis method and the variance analysis method in the orthogonal test, and analyzed the performance of the recycled aggregate permeable concrete based on the orthogonal test; after that, 
this study tested the mechanical properties and durability of the recycled aggregate permeable concrete via experiments and gave the corresponding test results and analysis. In the experiment part, this paper gave the measurement results of the compressive strength of the recycled aggregate permeable concrete under different water-cement ratios and different replacement rates of recycled aggregate, and plotted loaddisplacement curves of the test pieces in the compression test and the bending test. Moreover, comparative experiments were performed to analyze the influence of various factors (including replacement rate of recycled aggregate, ratio of cement aggregate, water-cement ratio, and ratio of sand) on the bending strength of the recycled aggregate permeable concrete. At last, the plotted curves of cumulative permeated water volume, permeated water volume increment, mass loss, and relative dynamic elastic modulus proved that the method of adding recycled aggregate to improve the freeze-thaw durability of recycled aggregate permeable concrete is effective.

\section{ACKNOWLEDGMENT}

This paper is based on the topic "Study on Surface Acoustic Waves with Nonlinear Multi-field Coupling” (YJZ-2019-13).

\section{REFERENCES}

[1] Jindal, A. (2021). Performance studies of pavement quality concrete mix incorporating beneficiated recycled concrete aggregates. Advances in Sustainable Construction Materials: Select Proceedings of ASCM 2020, 124: 87.

[2] Michaud, K., Hoult, N., Lotfy, A., Lum, P. (2016). Performance in shear of reinforced concrete slabs containing recycled concrete aggregate. Materials and Structures, $\quad 49(10)$ : 4425-4438. https://doi.org/10.1617/s11527-016-0798-4

[3] Sucic, A., Lotfy, A. (2016). Effect of new paste volume on performance of structural concrete using coarse and granular recycled concrete aggregate of controlled quality. Construction and Building Materials, 108: 119 128. https://doi.org/10.1016/j.conbuildmat.2015.10.064

[4] Sadati, S., Arezoumandi, M., Khayat, K.H., Volz, J.S. (2016). Shear performance of reinforced concrete beams incorporating recycled concrete aggregate and highvolume fly ash. Journal of Cleaner Production, 115: 284293. https://doi.org/10.1016/j.jclepro.2015.12.017

[5] Vieira, T., Alves, A., De Brito, J., Correia, J.R., Silva, R.V. (2016). Durability-related performance of concrete containing fine recycled aggregates from crushed bricks and sanitary ware. Materials \& Design, 90: 767-776. https://doi.org/10.1016/j.matdes.2015.11.023

[6] Zhang, F.J., Bai, G.L., Liu, C., Wu, H.R., Liu, Z.Q. (2016). Experimental study on compression performance of column made of recycled concrete with fly ash. Jianzhu Jiegou Xuebao/Journal of Building Structures, 37(S2):

30-35. https://doi.org/10.14006/j.jzjgxb.2016.S2.005

[7] Gonzalez-Corominas, A., Etxeberria, M., Galindo, A. (2016). Steam Curing Influence on Fly Ash HighPerformance Recycled Concrete. ACI Materials Journal, 113(6): 815-825.
[8] Sadati, S., Khayat, K.H. (2016). Field performance of concrete pavement incorporating recycled concrete aggregate. Construction and Building Materials, 126: 691-700.

https://doi.org/10.1016/j.conbuildmat.2016.09.087

[9] Gales, J., Parker, T., Cree, D., Green, M. (2016). Fire performance of sustainable recycled concrete aggregates: mechanical properties at elevated temperatures and current research needs. Fire Technology, 52(3): 817-845. https://doi.org/10.1007/s10694-015-0504-z

[10] Collery, D.J., Paine, K.A., Dhir, R.K. (2015). Establishing rational use of recycled aggregates in concrete: a performance-related approach. Magazine of Concrete Research, 67(11): 559-574. https://doi.org/10.1680/macr.14.00206

[11] Pawelska-Mazur, M., Kaszynska, M. (2021). Mechanical performance and environmental assessment of sustainable concrete reinforced with recycled end-of-life tyre fibres. Materials, 14(2): 256. https://doi.org/10.3390/ma14020256

[12] Raza, A., Rashedi, A., Rafique, U., Hossain, N., Akinyemi, B., Naveen, J. (2021). On the structural performance of recycled aggregate concrete columns with glass fiber-reinforced composite bars and hoops. Polymers, 13(9): 1508 . https://doi.org/10.3390/polym13091508

[13] Kannan, S., Arunachalam, K., Brindha, D. (2021). Performance analysis of recycled aggregate concrete with chemical admixture. Structural Concrete, 22: E8E21. https://doi.org/10.1002/suco.201900380

[14] Choi, Y.S., Lee, S.M. (2021). Fundamental properties and radioactivity shielding performance of concrete recycled cathode ray tube waste glasses and electric arc furnace slag as aggregates. Progress in Nuclear Energy, 133: 103649. https://doi.org/10.1016/j.pnucene.2021.103649

[15] Kachouh, N., El-Hassan, H., El-Maaddawy, T. (2019). Effect of steel fibers on the performance of concrete made with recycled concrete aggregates and dune sand. Construction and Building Materials, 213: 348-359. https://doi.org/10.1016/j.conbuildmat.2019.04.087

[16] Zhang, H., Wu, J., Jin, F., Zhang, C. (2019). Effect of corroded tension reinforcements on flexural performance of reinforced recycled aggregate concrete beams strengthened with CFRP. Composites Part B: Engineering, 162: 589-599. https://doi.org/10.1016/j.compositesb.2019.01.039

[17] Barroqueiro, T., da Silva, P.R., de Brito, J.D. (2019). Fresh-state and mechanical properties of highperformance self-compacting concrete with recycled aggregates from the precast industry. Materials, 12(21): 3565. https://doi.org/10.3390/ma12213565

[18] Ghorbel, E., Limaiem, M., Wardeh, G. (2021). Mechanical performance of bio-based FRP-confined recycled aggregate concrete under uniaxial compression. Materials, $14(7)$ : https://doi.org/10.3390/ma14071778

[19] Ilango, S., Singh, V., Gogoi, C. (2021). Effect of fly ash cement and polypropylene fibre on the performance of recycled aggregate concrete column under thermal loading: Experimental and numerical study. Australian Journal of Structural Engineering, 22(1): 42-58. https://doi.org/10.1080/13287982.2021.1872994 
[20] Sunayana, S., Barai, S.V. (2019). Performance of fly ash incorporated recycled aggregates concrete column under axial compression: Experimental and numerical study. Engineering Structures, 196: 109258. https://doi.org/10.1016/j.engstruct.2019.05.099

[21] Nematzadeh, M., Baradaran-Nasiria, A. (2019). Mechanical performance of fiber-reinforced recycled refractory brick concrete exposed to elevated temperatures. Computers and Concrete, 24(1): 19-35. https://doi.org/10.12989/cac.2019.24.1.019

[22] Ali, B., Qureshi, L.A. (2019). Influence of glass fibers on mechanical and durability performance of concrete with recycled aggregates. Construction and Building Materials, 228: 116783. https://doi.org/10.1016/j.conbuildmat.2019.116783

[23] Gonzalez-Corominas, A., Etxeberria, M., Fernandez, I. (2017). Structural behaviour of prestressed concrete sleepers produced with high performance recycled aggregate concrete. Materials and Structures, 50(1): 1-14. https://doi.org/10.1617/s11527-016-0966-6

[24] Borg, R.P., Baldacchino, O., Ferrara, L. (2016). Early age performance and mechanical characteristics of recycled PET fibre reinforced concrete. Construction and Building Materials, 108: 29-47. https://doi.org/10.1016/j.conbuildmat.2016.01.029
[25] Pedro, D., De Brito, J., Evangelista, L. (2015). Performance of concrete made with aggregates recycled from precasting industry waste: Influence of the crushing process. Materials and Structures, 48(12): 3965-3978. https://doi.org/10.1617/s11527-014-0456-7

[26] Omrane, M., Kenai, S., Kadri, E.H., Aït-Mokhtar, A. (2017). Performance and durability of self compacting concrete using recycled concrete aggregates and natural pozzolan. Journal of Cleaner Production, 165: 415-430. https://doi.org/10.1016/j.jclepro.2017.07.139

[27] Ardalan, N., Wilson, D., Larkin, T. (2017). Laboratory Performance of Recycled Concrete Aggregate as Basecourse Material. In Australasian Transport Research Forum (ATRF), 39th, 2017, Auckland, New Zealand.

[28] McCulloch, T., Kang, D., Shamet, R., Lee, S.J., Nam, B.H. (2017). Long-term performance of recycled concrete aggregate for subsurface drainage. Journal of Performance of Constructed Facilities, 31(4): 04017015. https://doi.org/10.1061/(ASCE)CF.1943-5509.0000994

[29] Wang, X., Liu, B., Zhang, C. (2017). Cyclic torsion performance of recycled aggregate concrete beams with or without fly ash. Construction and Building Materials, 132:

529-542. https://doi.org/10.1016/j.conbuildmat.2016.12.022 